\title{
Design and Experimental Validation for Direct-Drive Fault-Tolerant Permanent-Magnet Vernier Machines
}

\author{
Guohai Liu, Junqin Yang, Ming Chen, and Qian Chen \\ School of Electrical and Information Engineering, Jiangsu University, Zhenjiang 212013, China \\ Correspondence should be addressed to Guohai Liu; ghliu@ujs.edu.cn
}

Received 11 April 2014; Accepted 2 June 2014; Published 17 June 2014

Academic Editor: Wenxiang Zhao

Copyright ( 2014 Guohai Liu et al. This is an open access article distributed under the Creative Commons Attribution License, which permits unrestricted use, distribution, and reproduction in any medium, provided the original work is properly cited.

\begin{abstract}
A fault-tolerant permanent-magnet vernier (FT-PMV) machine is designed for direct-drive applications, incorporating the merits of high torque density and high reliability. Based on the so-called magnetic gearing effect, PMV machines have the ability of high torque density by introducing the flux-modulation poles (FMPs). This paper investigates the fault-tolerant characteristic of PMV machines and provides a design method, which is able to not only meet the fault-tolerant requirements but also keep the ability of high torque density. The operation principle of the proposed machine has been analyzed. The design process and optimization are presented specifically, such as the combination of slots and poles, the winding distribution, and the dimensions of PMs and teeth. By using the time-stepping finite element method (TS-FEM), the machine performances are evaluated. Finally, the FT-PMV machine is manufactured, and the experimental results are presented to validate the theoretical analysis.
\end{abstract}

\section{Introduction}

Currently, the permanent-magnet vernier (PMV) machine is becoming a promising candidate for direct-drive application such as the electric vehicle propulsion and the wind power generation [1-4]. For conventional direct-drive motor topologies, magnetic circuits with a large number of poles, slots, and windings are usually required to generate high torque at low speed. Such machine design will inevitably increase the machine volume and weight. However, it has been verified that a PMV machine with concentrated windings can offer high torque capability at low speed while reducing the number of slots and thus copper loss $[1,3,4]$. Based on the "magnetic gearing effect" [5, 6], PMV machines can effectively modulate the high-speed rotating field of the armature windings and the low-speed rotating field of the PM outer rotor by adopting the flux-modulation poles (FMPs). Hence, the armature poles number can differ from the rotor poles one, which breaks the traditional design rule of PM machines. Also, the volume of the stator with vernier structure will not increase with the large number of PM poles.

On the other hand, besides the requirements of high torque density, high reliability operation of motor drives is very important in such direct-drive applications $[7,8]$. Thus, the fault-tolerant capability of motor drives is becoming attractive. A number of researchers have investigated various motor topologies for fault-tolerant applications. Due to its simple and rugged construction, the switched reluctance motor has the advantage of fault-tolerant capability $[9,10]$. However, it still suffers from the drawback of relatively low power density. A PM machine is chosen in preference to switched reluctance motor due to its high power density, high efficiency, and equal fault-tolerance [11]. The key to fault tolerance in PM machines is to have both a sufficiently high phase inductance to limit short circuit currents and a sufficiently low mutual inductance between phases to avoid the performance degradation in the remaining healthy phases. Design methods of special slot-pole combination and concentrated windings can offer this characteristic as demonstrated in [11]. In addition, the increase of the phase number is also an effective way to improve reliability in motor drives. Actually, fault-tolerant feature is a significant advantage of multiphase machines over conventional three-phase machines [12]. For example, in a five-phase PM machine, the loss of up to three phases will not prevent the machine from continuous operation or even startup. 
In this paper, a five-phase fault-tolerant PMV (FT-PMV) machine will be analyzed and designed, aiming to incorporate the merits of the PMV machine and the fault-tolerant machine. The operation principle of the proposed machine will be presented. The design process and optimization are presented specifically, such as the combination of slots and poles, the winding distribution, and the dimensions of PMs and teeth. By using the time-stepping finite element method (TS-FEM), the machine performances will be assessed. Finally, experimental results will be provided to validate the theoretical analysis.

\section{Principle of Operation}

The key of a PMV machine is the introduction of FMPs. Its function is to modulate the high-speed rotating field generated by armature windings to the low-speed rotating field in the air-gap. This low-speed rotating air-gap field in turn interacts with the PM poles surface-mounted on the outer rotor, thus creating the desired low-speed high-torque operation. Since this operating principle is based on the "magnetic gearing effect," the relationship among the number of PMs pole pairs, armature winding fundamental pole pairs, and FMPs should be satisfied.

The number of pole pairs in the space harmonics of the flux density distribution and the corresponding rotational speed can be expressed as

$$
\begin{aligned}
& p_{i, m, k}=\left|m p_{i}+k n_{s}\right|, \\
& \omega_{i, m, k}=\frac{m p_{i} \omega_{i}}{\left|m p_{i}+k n_{s}\right|},
\end{aligned}
$$

where $m=1,3,5, \ldots$ (according to all the PMs with different pole pairs and most concentrated windings) and $k=0, \pm 1, \pm 2, \ldots, i=1,2$, and $i=1$ implies that the harmonic component is excited by the armature windings, while $i=2$ means that it is excited by the outer rotor PMs, $n_{s}$ is the number of the FMPs, and $\omega_{1}$ and $\omega_{2}$ are the rotational speeds of the armature fundamental field and outer rotor, respectively. For a clear discussion, it is assumed that the harmonic component is excited by the armature windings; namely, $i=1$. Meanwhile, the maximum harmonic component only can be obtained based on $k= \pm 1$ after modulation. So, by selecting $k=-1$ (1) can be rewritten as

$$
\begin{aligned}
& p_{1, m,-1}=n_{s}-m p_{1}, \\
& \omega_{1, m,-1}=\frac{m p_{1} \omega_{1}}{n_{s}-m p_{1}} .
\end{aligned}
$$

In order to transmit torque at different speeds, the pole pairs of the outer PMs $\left(p_{2}\right)$ must be equal to $p_{1, m,-1}$; namely, $p_{2}=n_{s}-m p_{1}, \omega_{2}=m p_{1} \omega_{1} / n_{s}-m p_{1}$. Thus, the high-to-low speed ratio $G_{r}$ is governed from (3) by

$$
G_{r}=\frac{\omega_{1}}{\omega_{2}}=\frac{n_{s}-m p_{1}}{m p_{1}} .
$$

Since $m$ is $1,3,5, \ldots$ (produced by Fourier decomposition), it is very necessary to get the optimal value of $m p_{1}$
TABLE 1: Machine design requirements.

\begin{tabular}{lc}
\hline Rated output power, $P$ & $1.8 \mathrm{Kw}$ \\
Rated current, $I_{s}$ (RMS) & $10 \mathrm{~A}$ \\
Rated speed, $n$ & $600 \mathrm{rpm}$ \\
Cooling method & Natural air convection \\
\hline
\end{tabular}

which means the order of the maximum magnetic field component induced by armature windings before modulation. When this $m p_{1}$ is determined, the value of $p_{1, m,-1}\left(n_{s}-\right.$ $m p_{1}$ ) can be easily obtained which means the order of the maximum magnetic field component induced by armature windings after modulation. As a result, only the PMs with $p_{2}$ pole-poles $\left(p_{2}=p_{1, m,-1}\right)$ interact with this biggest $p_{1, m,-1}$ th space harmonic, and the machine can produce the maximum torque.

Usually, in conventional PM machines [13], the fundamental stator space harmonic $p_{1}$ th is the biggest; namely, $m=1$. Actually, there is a traditional design rule that the number of pole pairs of fundamental stator space harmonic $p_{1}$ and the number of rotor PM pole pairs $p_{r}$ must be the same $\left(p_{1}=p_{r}\right)$. However, in the PM machines with fractionalslot concentrated windings (FSCWs) [14], this rule is not very necessary. The number of pole pairs of the fundamental stator space harmonic $p_{1}$ may be smaller than that of the $\mathrm{PM}$ rotor $p_{r}$. The torque is developed by the interaction of a higher order stator space harmonic with the PMs, which means $m \neq 1$. Only if the $m p$ th space harmonic interacts with the $p_{r}$ pole pairs PM rotor, the machine can produce maximum continuous useful torque, which means $m p_{1}=$ $p_{r}$. As a result, to determine the value of $p_{2}\left(p_{1, m,-1}\right.$ th $)$, a PMV machine should have found its "original PM machine" with $p_{r}$ pole pairs PMs, in which their armature windings are completely identical. This is due to $m p_{1}=p_{r}=n_{s}-$ $p_{2}$. To be concluded, various armature winding connections decide various vernier structures. The winding design of the proposed PMV machine will be presented in Section 3.2.

\section{Machine Design and Optimization}

First of all, the design objectives of the machine need to be clarified. The conventional design criteria are listed in Table 1. The outside stator radius $R_{1}$, machine length $L_{s}$, number of phases $N_{\text {ph }}$, current density $J_{a}$, and slot packing factor $k_{s}$ are kept invariant. Since naturally cooled condition is chosen, the current density cannot be very high. Also, both high torque density and high reliability are required. According to the operation principle of PMV machines discussed in Section 2, the aim of high torque density can be achieved by adopting the vernier structure. In this section, the faulttolerant design aimed to have high reliability will be detailed, while the vernier effect is still satisfied.

3.1. Main Dimensions. The initial design of any PM machine includes the determination of the outside stator radius $R_{1}$, the outside rotor radius $R_{2}$, the stack length $L_{s}$, and the air-gap length $R_{g}$. For a machine with specific flux density, electric 
TABLE 2: Basic parameters of two prototypes.

\begin{tabular}{lcccccc}
\hline Items & $S$ & $p_{r}$ & $m$ & $p_{1}$ & $n_{s}$ & $p_{2}\left(n_{s}-m p_{1}\right)$ \\
\hline Prototype_1 & 20 & 9 & 9 & 1 & 40 & 31 \\
Prototype_2 & 20 & 11 & 11 & 1 & 40 & 29 \\
\hline
\end{tabular}

and magnetic loading, and speed, its rated output power is proportional to the rotor volume. Usually, the air-gap length in PM machines has little impact on power since the permeance of PM is close to that of air. Hence, the thickness of PM is the dominant part in the flux path. However, for PMV machines, the harmonics in air-gap are used to produce torque, which means that PMV machines are very sensitive to the air-gap length. Meanwhile, compared with PM machines, PMV machines can have the thinner thickness of rotor and stator yoke due to their shorter flux path and larger pole number. Thus, the volume can be minimized. All these four parameters have been determined as a list in Table 3. The influences of the air-gap length, thickness of PM, and other critical parameters will be analyzed and discussed.

\subsection{Design of Stator, Phases, and Winding Configuration.} Since fault tolerance and high reliability are the foundations of this design, the minimum electrical, magnetic, and thermal interactions are required between phases. As a result, a fault in one phase does not undesirably affect the remaining healthy phases. These requirements can be satisfied by designing the appropriate armature windings with one-phase winding per slot. Meanwhile, this topology has a coil wound around a single tooth which is called single-layer FSCW (SLFSCWs). This solution enhances thermal isolation and minimizes mutual coupling between phases. In addition, overlaps between end-windings of different phases are eliminated, so that the volume of copper can be significantly reduced, in particular when the axial length of the machine is small. Considering that any PMV machine can be transformed by its "original PM machine" discussed in Section 2, an "original PM machine" can be designed firstly before introducing the vernier structure.

In any SL-FSCW PM machine, the basic winding module (with the smallest allowable number of slots and poles) has just two antiphase coils per phase. For any such winding with $N_{\text {ph }}$ phases and $S$ slots, the required number of PM pole pairs $p_{r}$ is given by [8]

$$
2 p_{r}=S\left(1 \pm \frac{n}{2 N_{\mathrm{ph}}}\right)
$$

where $n=1$, or $n=$ any nonzero odd integer less than $N_{\text {ph }}$, such that $n$ and $N_{\text {ph }}$ do not share any common factors. It should be noted that a good design necessitates a high coupling between the magnets and the coils, which implies that $n / N_{\text {ph }}$ should be no greater than about 0.6. For a PMV machine with FSCW, a large number of slots will result in a small per slot cross-section area and a large number of PMs which further reduce utilization of PMs and improve the operating frequency. Hence, $S$ cannot be too large. However, to improve the reliability further, electrical machines
TABLE 3: Machine design requirements.

\begin{tabular}{lc}
\hline Items & FT-PMV machine \\
\hline Phases, $N_{\mathrm{ph}}$ & 5 \\
Number of stator slots, $S$ & 20 \\
Number of rotor pole pairs, $p_{2}$ & 31 \\
Number of FMPs, $n_{s}$ & 40 \\
Gear ratio, $G_{r}$ & $-31: 9$ \\
Rated voltage, $U(\mathrm{~V})$ & 70 \\
Current density, $J_{a}\left(\mathrm{~A} / \mathrm{mm}^{2}\right)$ & 6.57 \\
Outside stator radius, $R_{1}(\mathrm{~mm})$ & 60 \\
Outside rotor radius, $R_{2}(\mathrm{~mm})$ & 70 \\
Stack length, $L_{s}(\mathrm{~mm})$ & 60 \\
Air-gap length $R_{g}(\mathrm{~mm})$ & 0.5 \\
PM thickness, $H_{\mathrm{pm}}(\mathrm{mm})$ & 3.2 \\
Fault-tolerant tooth, $L_{1}(\mathrm{~mm})$ & 1.9 \\
Armature tooth, $L_{2}(\mathrm{~mm})$ & 3.3 \\
PM pole-arc coefficient, $\alpha$ & 1 \\
Per slot area, $A_{\text {slot }}\left(\mathrm{mm}{ }^{2}\right)$ & 121.8 \\
Slot packing factor, $k_{s}$ & 0.6 \\
Stator turns per coil, $N_{c}$ & 48 \\
PM type & NdFe35
\end{tabular}

are generally designed with a high phase number, where a corresponding increase in the number of slots happens according to (5). As a result, a compromise between $S$ and $N_{\mathrm{ph}}$ is obtained with a selection of $S=20$ and $N_{\mathrm{ph}}=5$. Thus, three basic parameters of an "original PM machine" have been determined, in which $S, N_{\mathrm{ph}}$, and $p_{r}$ are 20, 5, 9, or 11 , respectively.

The winding configurations with $p_{r}=9$ and 11 are shown in Figure 1. Clearly, differing from the $p_{r}=11$ winding connection, the $p_{r}=9$ winding connection only has the opposite direction of the rotating magnetic field. It means that they will share the same space harmonic spectrums due to armature windings. So, the space harmonic spectrum of them is shown in Figure 2. It can be seen that the order of the biggest space harmonic content $m p_{1}$ is 9 or 11 before modulation, but the fundamental stator space harmonic $p_{1}$ is 1th. Obviously, $m p_{1}=p_{r}$ and $m \neq 1$ due to this kind of SL-FSCW configuration, validating the theoretical analysis in Section 2.

For the stator structure, only one adjustment is needed to transform the "original PM topology" to its corresponding PMV topology. It is to split the stator tooth into $n_{s}$ FMPs. By considering manufacturing technology, symmetry, vernier effect, and electromagnetic performance, $n_{s}=40$ is a better choice [15]. Up to here, basic structures of two prototypes have been designed as listed in Table 2. From Figure 2, it can 

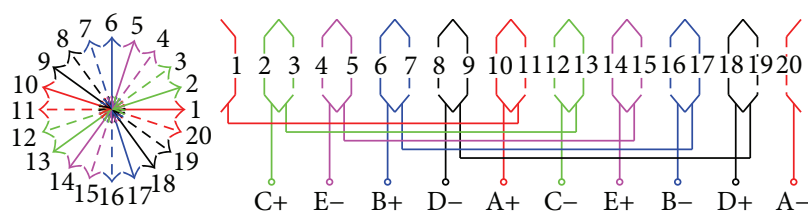

(a)

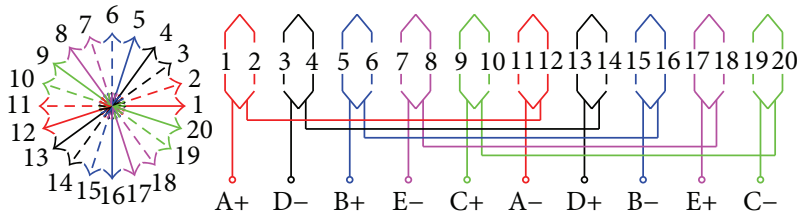

(b)

FIGURE 1: Winding configurations. (a) $p_{r}=9$. (b) $p_{r}=11$.

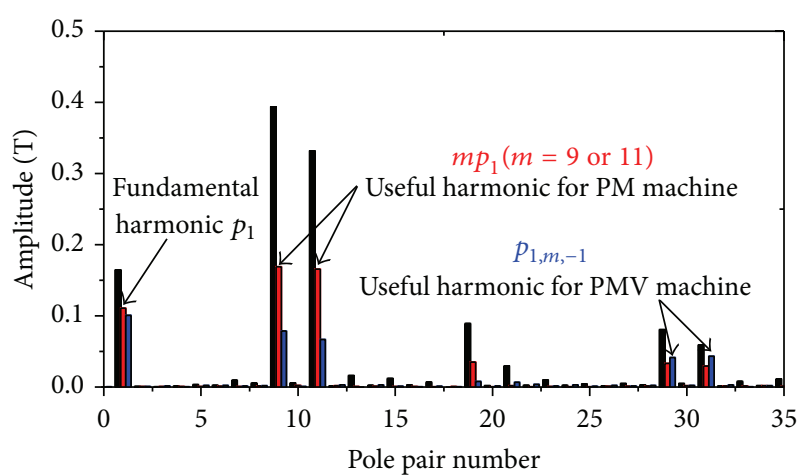

In stator yoke
In tooth under FMPs (before modulation)
In air gap (after modulation)

FIGURE 2: Space harmonic spectrum due to armature windings.

be clearly seen that the amplitudes of most harmonics are reduced in the air gap since the different permeances exist in the full flux path from stator yoke to air gap. However, the increased amplitudes of 31st and 29th are significant, which can be known from the comparison of red and blue columns. The reason is that the increased parts of 31st and 29th result from the maximum magnetic field components (9th and 11th) by modulation effect, which is in agreement with the theoretical analysis in Section 2. Thus, in order to produce the maximum torque, the number of $\mathrm{PM}$ pole pairs $p_{2}$ should be equal to 31 or 29 as listed in Table 2.

Furthermore, Figure 3 compares the space harmonic spectrums of both prototypes in the air gap due to the PMs. It also can be seen that, corresponding to $p_{2}$ pole pairs of the rotor rotating field, the highest asynchronous harmonic component is that with $p_{2, m,-1}$ pole pairs $\left(p_{2, m,-1}=\right.$ $\left.m p_{1}\right)$. Obviously, the effect of flux modulation is verified by Figures 2 and 3. A fault-tolerant machine with large number of PM poles can be designed by introducing the vernier structure, rather than the increase of the volume and the number of slots.

In order to find which prototype possesses the advantageous performance, Figure 4 shows the back-EMF waveforms at the speed of $600 \mathrm{rpm}$, and Figure 5 shows the output torque waveforms under the rated operation. It can be known that back-EMFs of both machines are almost the same, but that of the prototype_1 is a little more sinusoidal, and the root mean square (RMS) value is $17.1 \mathrm{~V}$. As a result, the average output

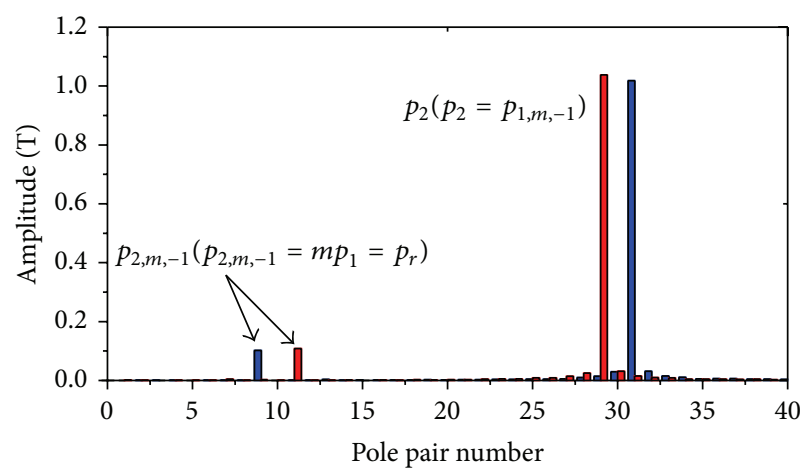

$\square$ Prototype_1

$\square$ Prototype_2

FIgURE 3: Space harmonic spectrum due to PMs.

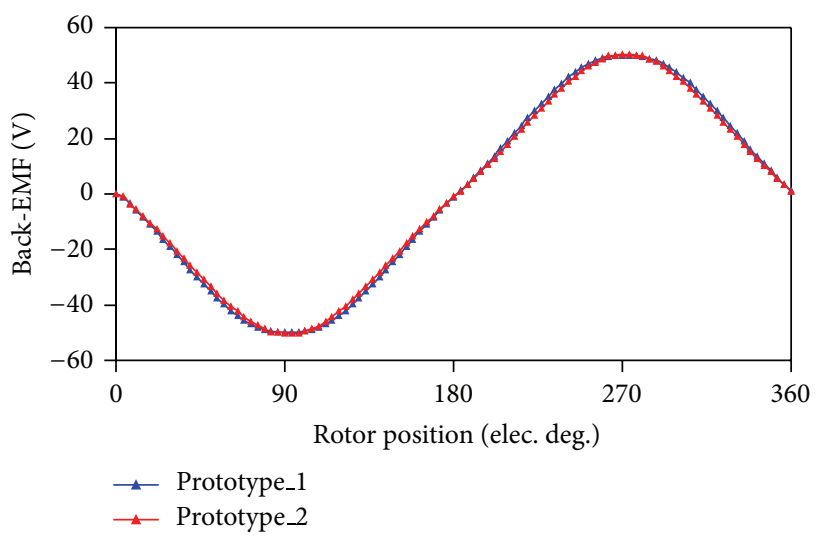

Figure 4: Comparison of back-EMF.

torque as shown in Figure 5 of prototype_1 is $1 \mathrm{Nm}$ larger than that of prototype $\_2$. Finally, prototype $\_1$ is selected.

3.3. Optimization of Air-Gap Length. As discussed above, PMV machines are very sensitive to the air-gap length. Figure 6 shows the variation of torque characteristics with air-gap length $R_{g}$. The torque transmission characteristics are obtained based on the locked-rotor operation. Obviously, the maximum output torque increases linearly when $R_{g}$ decreases. In addition, it can be seen that the current angle $\beta$ is almost equal to zero when $R_{g}$ is large, and $\beta$ increases with the decrease of $R_{g}$. This phenomenon occurs due to the flux concentration and the saturation at the FMPs top. Meanwhile, 


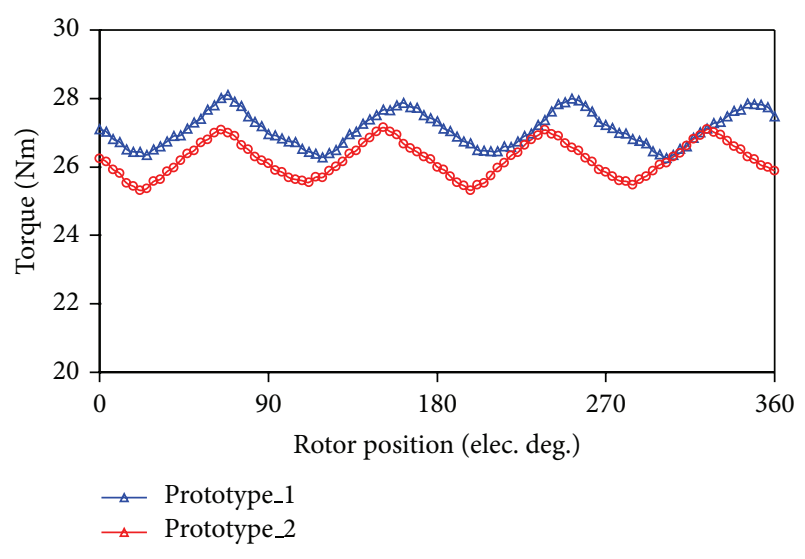

FIGURE 5: Comparison of output torque.

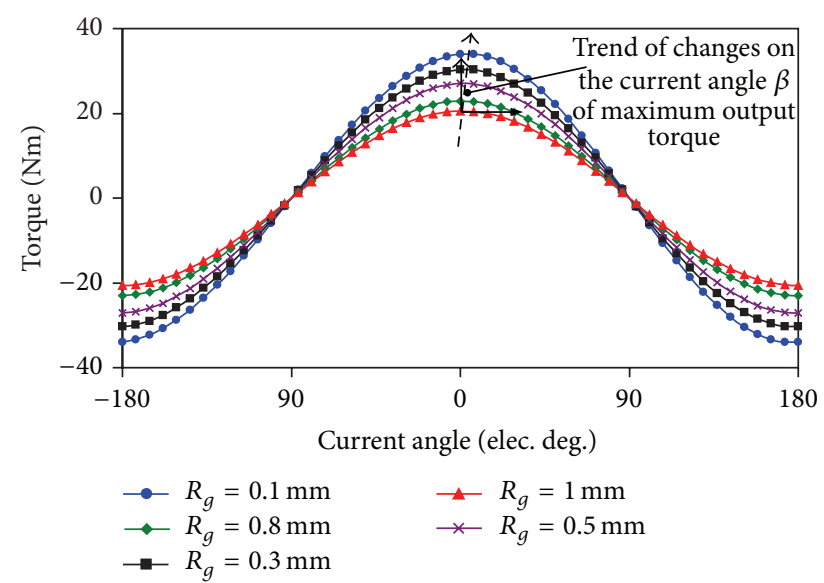

FIGURE 6: Variations of torque characteristic with air-gap length $R_{g}$.

it indicates that $L_{d}=L_{q}$, and thus reluctance torque has no contribution to the output torque when $R_{g}$ is large. By considering machining accuracy of the air-gap, $R_{g}=0.5 \mathrm{~mm}$ is chosen. With $R_{g}=0.5 \mathrm{~mm}, L_{d}$ can be thought to be equal to $L_{q}$ approximately, which means that the maximum torque per ampere control can be achieved by " $i_{d}=0$ " control method.

3.4. Magnet Design. The PM radial thickness $H_{\mathrm{pm}}$ is a significant parameter since it affects the flux density in the air gap, the demagnetization withstand capability, and the cost. In general, the increase of $H_{\mathrm{pm}}$ can enhance air-gap flux density and thus torque in PM machines. However, for surface-mounted PMV machines, the main function of $H_{\mathrm{pm}}$ is to increase the resistance to demagnetization. The peak value variations of the back-EMF and the cogging torque with $H_{\mathrm{pm}}$ are shown in Figure 7. Clearly, the amplitude of cogging torque increases with $H_{\mathrm{pm}}$ increasing all along, but only when $H_{\mathrm{pm}}<2 \mathrm{~mm}$, with $H_{\mathrm{pm}}$ increasing, the amplitude of backEMF increases. In fact, there is an optimal value of $H_{\mathrm{pm}}$ corresponding to the largest amplitude of back-EMF. It differs from PM machines where the larger the $H_{\mathrm{pm}}$ is, the larger the peak value of back-EMF becomes. This is due to the fact

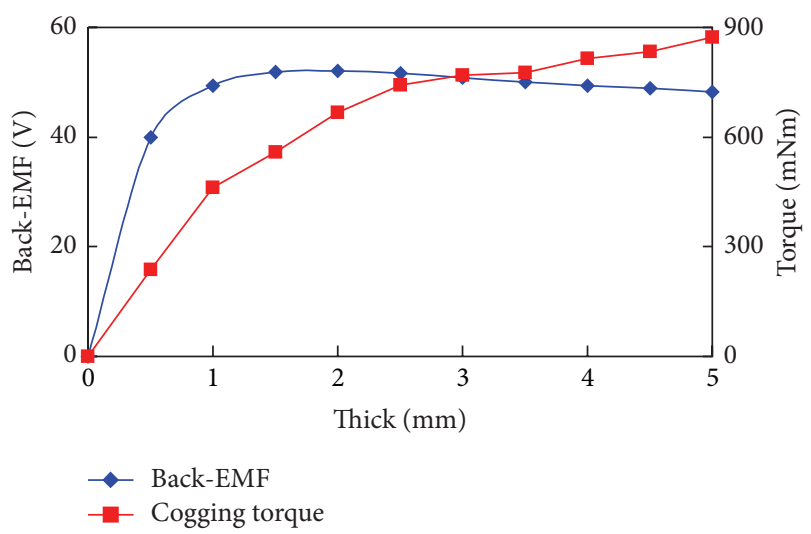

FIGURE 7: Peak value variations of back-EMF and cogging torque with PM radial thickness $H_{\mathrm{pm}}$.

that the reluctance is also increased with the increasing $H_{\mathrm{pm}}$. The permeance of PM is close to air which is far greater than that of stator or rotor iron. The reluctance increase will reduce space harmonic field in air gap, thus reducing the back-EMF amplitude. Hence, the value of $H_{\mathrm{pm}}$ must be optimized by considering the back-EMF amplitude.

Partial demagnetization of PMs can influence motor performances of both voltage and torque seriously. The motor temperature, the magnitude of current, and the power angle can determine the partial demagnetization [16]. In this work, the partial demagnetization is investigated when $i_{d}=i_{s}$ and $i_{q}=0$ strategy is adopted at the operation temperature of $120^{\circ} \mathrm{C}$. It means that the rated current is completely used for demagnetization in order to simulate an abominable operating condition for PMs. By this way, the variation of the minimum flux density in PMs with PM radial thickness is shown in Figure 8. It can be seen that the increase of $H_{\mathrm{pm}}$ can effectively increase the resistance to demagnetization. As NdFe35 PM material is usually employed, the flux density in PMs less than $0.2 \mathrm{~T}$ can be thought as irreversible demagnetization. As a result, $H_{\mathrm{pm}}=3.2 \mathrm{~mm}$ is selected. With $H_{\mathrm{pm}}=$ $3.2 \mathrm{~mm}$, the proposed machine can provide a good backEMF. Moreover, it can avoid the irreversible demagnetization of the PMs to a great extent.

The pole-arc coefficient $\alpha$ of PMs also has great effects on back-EMF and cogging torque. An appropriate $\alpha$ can increase the back-EMF and reduce the cogging torque. In most cases, a compromise between the low cogging torque and high backEMF should be considered. For a PMV machine, its $\alpha$ only influences the peak values of the back-EMF and the cogging torque, rather than their shapes. Figure 9 shows the peak value variations of the back-EMF and the cogging torque with different pole-arc coefficient $\alpha$. It can be seen that the peak cogging torque is relatively small, although it increases when $\alpha$ increases. However, the peak back-EMF increases greatly when $\alpha$ increases. Finally, by considering the easy assembling, $\alpha=1$ is selected.

3.5. Optimization of Tooth Width. Tooth width can affect slot area and saturation level on tooth; thus it has a great 


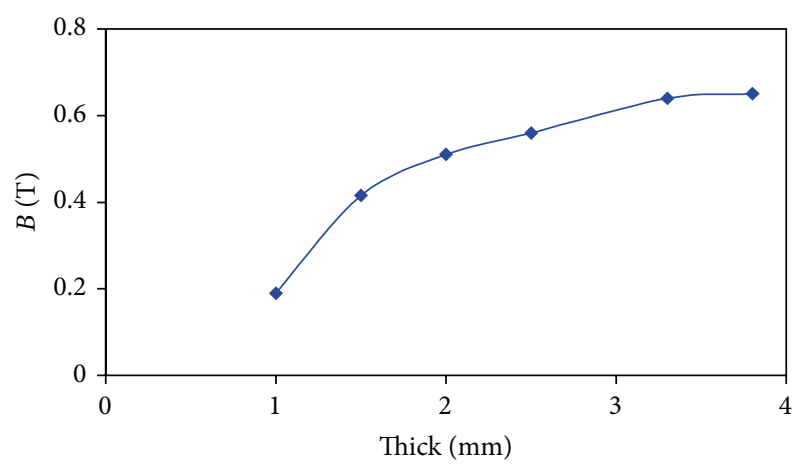

FIGURE 8: Variation of minimum flux density in PMs with PM radial thickness $H_{\mathrm{pm}}$.

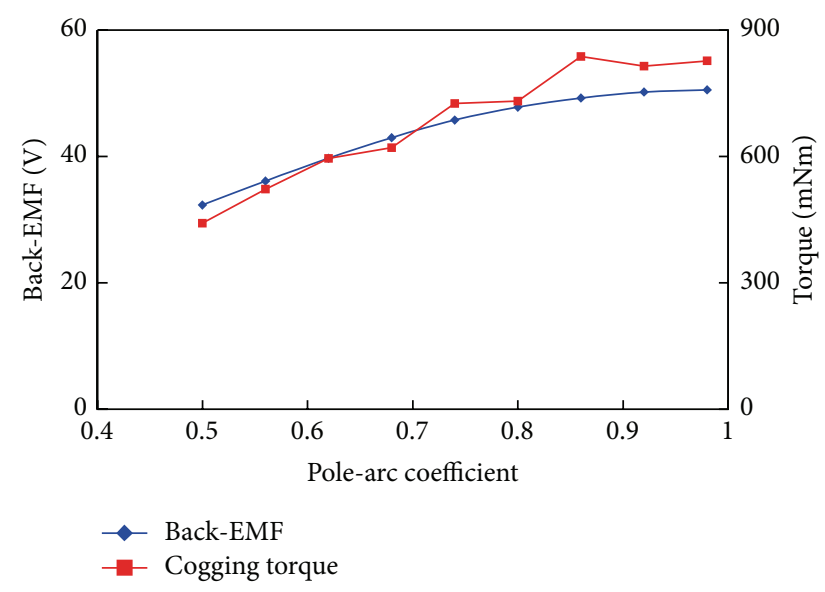

Figure 9: Peak value variations of back-EMF and cogging torque with PM pole-arc coefficient $\alpha$.

influence on output torque. With SL-FSCWs, the proposed FT-PMV machine has a coil wound on alternate teeth called armature tooth. The unwound teeth are usually called faulttolerant tooth, which provide a special flux path to decrease the electromagnetic coupling between phases. Tooth width of fault-tolerant tooth $L_{1}$ can be unequal to that of armature tooth $L_{2}$ to optimize the flux linkage and enlarge the slot area as possible without performance degradation [13]. The variation of average output torque with tooth width is shown in Figure 10. Firstly, $L_{2}$ can be optimized by assuming $L_{2}=L_{1}$ as shown in Figure 10 (blue curve). It can be seen that the average output torque tended to be a constant when $L_{2}$ and $L_{1}$ are over $3.3 \mathrm{~mm}$. Then, after determining $L_{2}=3.3 \mathrm{~mm}$, the optimal value of $L_{1}$ can be found as shown in Figure 10 (red curve). Clearly, the average output torque remains unchanged when $L_{1}>1.9 \mathrm{~mm}$, which means that all the flux lines can run through the fault-tolerant tooth just with $L_{1}=1.9 \mathrm{~mm}$. Finally, $L_{2}=3.3 \mathrm{~mm}$ and $L_{1}=1.9 \mathrm{~mm}$ are selected, which have the same effect as $L_{2}=L_{1}=3.3 \mathrm{~mm}$. Based on this optimal value of tooth width, the slot area can be significantly enlarged.

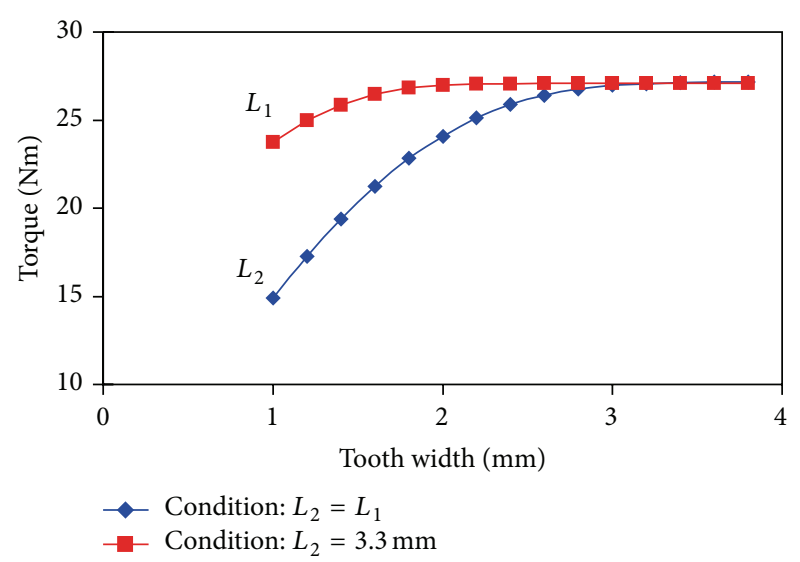

FIGURE 10: Variation of average output torque with fault-tolerant tooth width $L_{1}$ and armature tooth width $L_{2}$.

3.6. Final Solution. The detailed dimensions, materials, and structure parameters are listed in Table 3. The cross section of the proposed FT-PMV machine is shown in Figure 11(a). Meanwhile, a partial amplification of the cross section is given in Figure 11(b), in which the corresponding important structure parameters are marked. It should be noted that, in this design, the FMP-slot width $\theta_{1}$, FMP width $\theta_{2}$, and stator slot opening width $\theta_{3}$ are made equal $\left(\theta_{1}=\theta_{2}=\theta_{3}\right)$. In addition, FMP-slot depth $L_{3}$ is set to be $4 \mathrm{~mm}$. In fact, as $L_{3}$ changes between $2 \mathrm{~mm}$ and $5 \mathrm{~mm}$, the performances of the proposed machine almost remain unchanged.

\section{Simulated Performance}

In order to verify the advantages of the proposed FT-PMV machine, its performance is analyzed by using TS-FEM.

4.1. Torque Performance. While the FMPs provide unique magnetic path to modulate between the rotor field and the stator field, there are different air-gap lengths at different positions, for example, different magnetic resistance. Thus, the interaction between the FMPs and the PMs causes the cogging torque. Figure 12 shows the predicted cogging torque. The peak value of the cogging torque is $0.88 \mathrm{Nm}$. In addition, the static torque waveform of the proposed FTPMV machine in BLAC operation mode is also shown in Figure 12. It can be clearly observed that the output torque ripple induces mainly due to the cogging torque. It has been known that, for the PM machines operated in BLAC mode, the harmonic distortion in the back-EMF and the cogging torque are the two main sources of ripple in the output torque [16]. For a five-phase machine only the $5 k \pm 1$ th $(5 k \pm 1 \neq 3 j, k$, $j$ is an integer) harmonic components will contribute to the generation of torque ripple. In fact, the harmonic components of the back-EMF of the proposed machine will hardly ever result in the torque ripple, which will be verified in Section 5 .

4.2. Fault-Tolerant Capability. The self-inductance and the mutual inductance between phases have been calculated as 


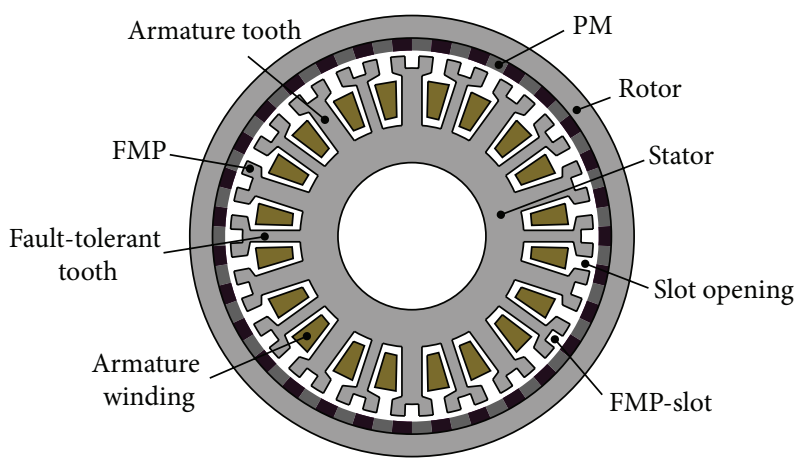

(a)

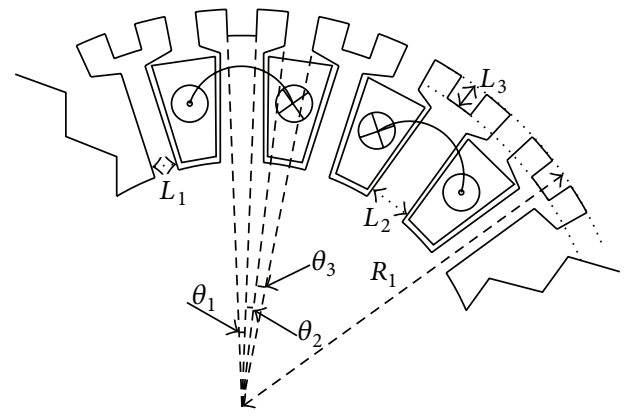

(b)

Figure 11: Proposed FT-PMV machine. (a) Cross section. (b) Parameters.

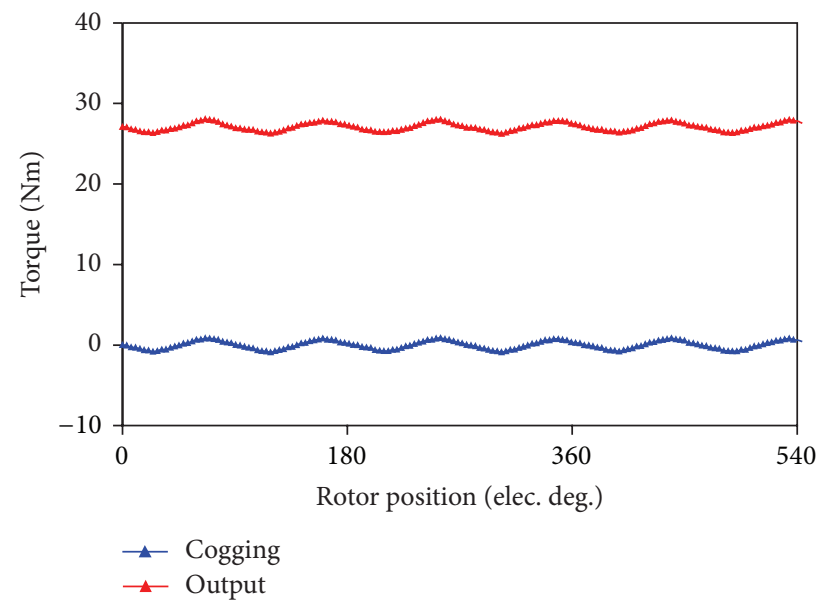

FIGURE 12: Cogging torque and output torque waveforms.

listed in Table 4. It can be seen that the proposed machine has the very low ratios of the mutual inductance to the self-inductances, showing that there is nearly zero magnetic coupling between phases. Namely, a fault in one phase does not undesirably affect the remaining healthy phases. Besides, inductance affects the power factor greatly, which can be seen from the following formula:

$$
\mathrm{PF}=\frac{1}{\sqrt{1+\left(L_{s} I / \psi_{m}\right)}},
$$

where $\psi_{m}$ is the magnet flux linkage, $I$ is the rms phase current, and $L_{s}$ is the synchronous inductance. However, the influence of inductance to the power factor is not absolute. In fact, when the electric load of the motor is determined, the change on power factor would be unconspicuous, regardless of the changes of other parameters.

Figure 13 shows the current responses under the shortcircuit fault condition at the speed of $600 \mathrm{rpm}$. Only one phase is short-circuit, and other phases operate normally. It can be seen that the short-circuit current is limited well. Hence, it can be concluded that the proposed machine can offer high fault-tolerant capability.
TABLE 4: Comparison of inductances.

\begin{tabular}{lccccc}
\hline Items & A-A & A-B & A-C & A-D & A-E \\
\hline Inductance (mH) & 3.22 & 0.0033 & 0.0113 & 0.0113 & 0.0033 \\
Ratio (\%) & 100 & 0.102 & 0.35 & 0.35 & 0.102 \\
\hline
\end{tabular}

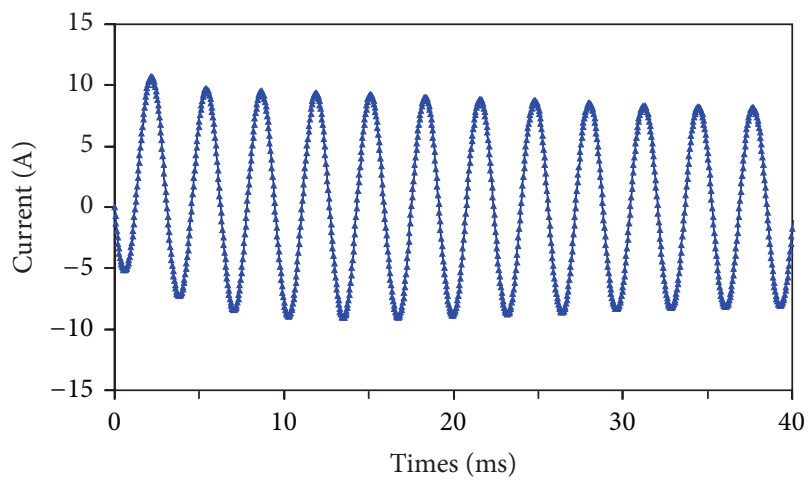

FIGURE 13: Short-circuit current.

\section{Experimental Validation}

The proposed FT-PMV machine is fabricated and tested to verify the theoretical analysis, which is shown in Figure 14. Clearly, the above discussed fault-tolerant tooth, unequal tooth width, SL-FSCW, and FMP design are adopted in the stators of the prototype.

The measured phase back-EMFs at the speed of $600 \mathrm{rpm}$ are shown in Figure 15, which agrees with the simulated results in Figure 4. The measured value is about $8 \%$ lower than the predicted; both lamination factor and end effect are the key affective factors that contributed to this result. Furthermore, the harmonic spectrum of the measured phase back-EMFs is normalized by the respective fundamental components as shown in Figure 16. The total harmonic distortion (THD) is $3.2 \%$. Hence, the proposed machine is very suitable for BLAC operation. Moreover, it can be seen that the contents of harmonics of the proposed machine which is useful for the torque ripple are almost none. Hence, 


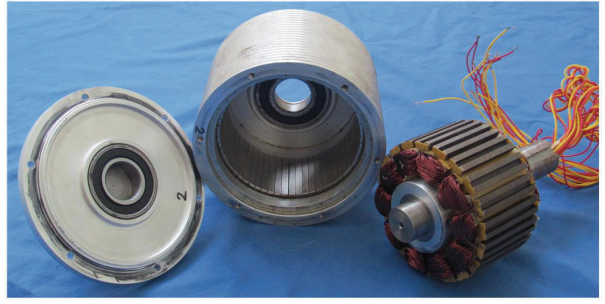

(a)

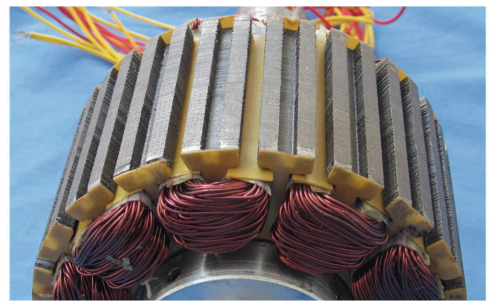

(b)

FIGURE 14: Prototype machine. (a) Stator and rotor assembly. (b) FMPs in stator.

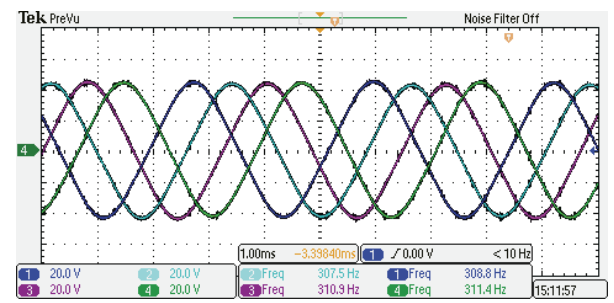

FIGURE 15: Measured phase back-EMFs (1 ms/div, $20 \mathrm{~V} / \mathrm{div})$.

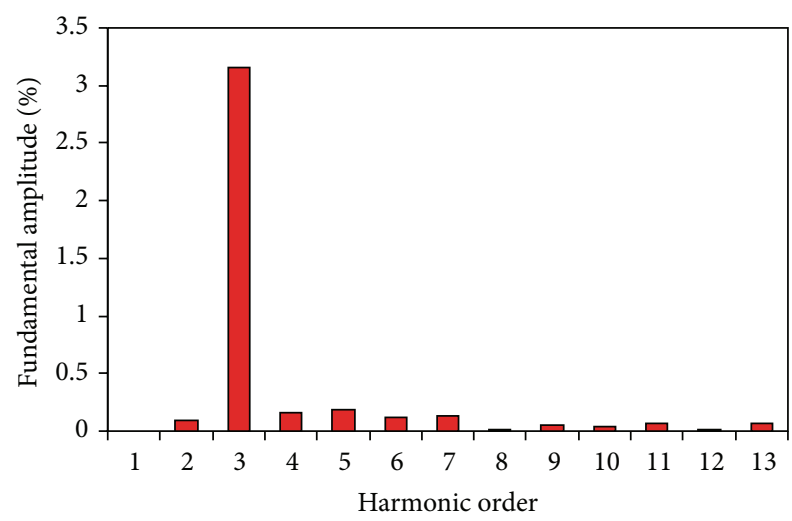

FIGURE 16: Harmonic distributions of back-EMF.

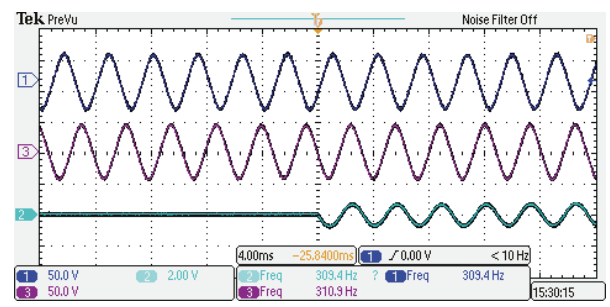

FIGURE 17: Measured short-circuit current and adjacent phase backEMFs (4 ms/div, 50 V/div, $20 \mathrm{~A} /$ div, $50 \mathrm{~V} /$ div).

the output torque ripple mainly results from the cogging torque.

Figure 17 shows the measured current responses under the short-circuit fault condition at the speed of $600 \mathrm{rpm}$. Also, the measured adjacent phase back-EMFs are shown together. It can be seen that the short-circuit current is limited well, which agrees with the simulated results in Figure 13. Meanwhile, it can be observed that the back-EMFs are not affected entirely by the adjacent short-circuit current. So, it can be concluded that the independence between adjacent phases in the proposed FT-PMV machine is high, and it can offer high fault-tolerance [16].

\section{Conclusion}

In this paper, a FT-PMV machine has been designed, analyzed, and tested. The operation principle of the proposed machine has been presented. The design process and optimization have been discussed specifically, such as the combination of slots and poles, the winding distribution, and the dimensions of PMs and tooth width. By using the TS-FEM, the machine performance has been assessed. Compared with its PMV counterpart, the proposed machine can offer high fault-tolerant performance, thus improving the machine reliability. Compared with its fault-tolerant counterpart, the PMV structure of the proposed machine can offer a high torque density nearly up to $30 \mathrm{Nm} / \mathrm{L}$, thus reducing the machine volume and weight. Finally, a prototype has been manufactured, and experimental results are provided to validate the theoretical analysis.

\section{Nomenclature}

$\alpha$ : Pole-arc coefficient

$H_{\mathrm{pm}}$ : Permanent magnet thickness

$\tau$ : $\quad$ Pole pitch

$N_{\text {ph }}$ : Number of phases

$A_{\text {slot }}$ : Per slot area

$J_{a}: \quad$ Current density

$N_{c}:$ Stator turns per coil

$R_{g}$ : Air-gap length

$L_{1}$ : Fault-tolerant tooth width

$L_{2}$ : Armature tooth width

$L_{3}$ : FMP-slot depth

$L_{s}$ : Stack length

$R_{1}$ : Outside stator radius

$R_{2}$ : Outside rotor radius

$\theta_{1}$ : FMP-slot width

$\theta_{2}: \quad$ FMP width

$\theta_{3}$ : Stator slot opening width

$p_{1}$ : Pole pairs of the fundamental stator space harmonic

$p_{2}$ : Pole pairs of the PMs of PMV machines

$p_{r}$ : Pole pairs of the PMs of conventional PM machines. 


\section{Conflict of Interests}

The authors declare that they have no conflict of interests regarding the publication of this paper.

\section{Acknowledgments}

This work was supported in part by the National Natural Science Foundation of China (Projects 61273154 and 51277194), by the Specialized Research Fund for the Doctoral Program of Higher Education of China (Project 20123227110012), by the Natural Science Foundation of Jiangsu Province (BK20130011), and by the Priority Academic Program Development of Jiangsu Higher Education Institutions.

\section{References}

[1] J. Li, K. T. Chau, J. Z. Jiang, C. Liu, and W. Li, "A new efficient permanent-magnet vernier machine for wind power generation," IEEE Transactions on Magnetics, vol. 46, no. 6, pp. $1475-1478,2010$.

[2] W. Li, K. T. Chau, C. Liu, S. Gao, and D. Wu, "Analysis of toothtip flux leakage in surface-mounted permanent magnet linear vernier machines," IEEE Transactions on Magnetics, vol. 49, no. 7, pp. 3949-3952, 2013.

[3] L. Xu, J. Ji, G. Liu, Y. Du, and H. Liu, "Design and analysis of linear fault-tolerant permanent-magnet vernier machines," The Scientific World Journal, vol. 2014, Article ID 483080, 8 pages, 2014.

[4] S.-U. Chung, J.-W. Kim, B.-C. Woo, D.-K. Hong, J.-Y. Lee, and D.-H. Koo, "A novel design of modular three-phase permanent magnet vernier machine with consequent pole rotor," IEEE Transactions on Magnetics, vol. 47, no. 10, pp. 4215-4218, 2011.

[5] K. Atallah, S. D. Calverley, and D. Howe, "Design, analysis and realisation of a high-performance magnetic gear," IEE Proceedings: Electric Power Applications, vol. 151, no. 2, pp. 135143, 2004

[6] L. Jian, G. Xu, C. C. Mi, K. T. Chau, and C. C. Chan, "Analytical method for magnetic field calculation in a low-speed permanent-magnet harmonic machine," IEEE Transactions on Energy Conversion, vol. 26, no. 3, pp. 862-870, 2011.

[7] W. Zhao, M. Cheng, K. T. Chau, R. Cao, and J. Ji, "Remedial injected-harmonic-current operation of redundant fluxswitching permanent-magnet motor drives," IEEE Transactions on Industrial Electronics, vol. 60, no. 1, pp. 151-159, 2013.

[8] W. Zhao, M. Cheng, W. Hua, H. Jia, and R. Cao, "BackEMF harmonic analysis and fault-tolerant control of fluxswitching permanent-magnet machine with redundancy," IEEE Transactions on Industrial Electronics, vol. 58, no. 5, pp. 19261935, 2011.

[9] H. Torkaman and E. Afjei, "Sensorless method for eccentricity fault monitoring and diagnosis in switched reluctance machines based on stator voltage signature," IEEE Transactions on Magnetics, vol. 49, no. 2, pp. 912-920, 2013.

[10] M. Ruba, I. A. Viorel, and L. Szabo, "Modular stator switched reluctance motor for fault tolerant drive systems," IET Electric Power Applications, vol. 7, no. 3, pp. 159-169, 2013.

[11] Q. Chen, G. Liu, W. Gong, and W. Zhao, "A new fault-tolerant permanent-magnet machine for electric vehicle applications," IEEE Transactions on Magnetics, vol. 47, no. 10, pp. 4183-4186, 2011.
[12] E. Levi, "Multiphase electric machines for variable-speed applications," IEEE Transactions on Industrial Electronics, vol. 55, no. 5, pp. 1893-1909, 2008.

[13] G. Liu, W. Gong, Q. Chen, L. Jian, Y. Shen, and W. Zhao, "Design and analysis of new fault-tolerant permanent magnet motors for four-wheel-driving electric vehicles," Journal of Applied Physics, vol. 111, no. 7, Article ID 07E713, 2012.

[14] P. B. Reddy, A. M. El-Refaie, and K. K. Huh, "Generalized approach of stator shifting in interior permanent-magnet machines equipped with fractional-slot concentrated windings," IEEE Transactions on Industrial Electronics, vol. 61, no. 9, pp. 5035-5046, 2014.

[15] G. Liu, J. Yang, W. Zhao, J. Ji, Q. Chen, and W. Gong, "Design and analysis of a new fault-tolerant permanent-magnet vernier machine for electric vehicles," IEEE Transactions on Magnetics, vol. 48, no. 11, pp. 4176-4179, 2012.

[16] Q. Chen, G. Liu, W. Zhao, M. Shao, L. Sun, and Z. Liu, "Design and comparison of two fault-tolerant interior permanentmagnet motors," IEEE Transactions on Industrial Electronics, 2014. 


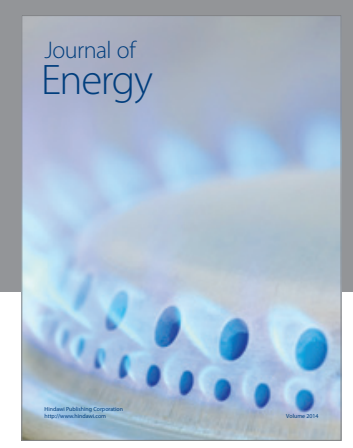

Journal of

Industrial Engineering
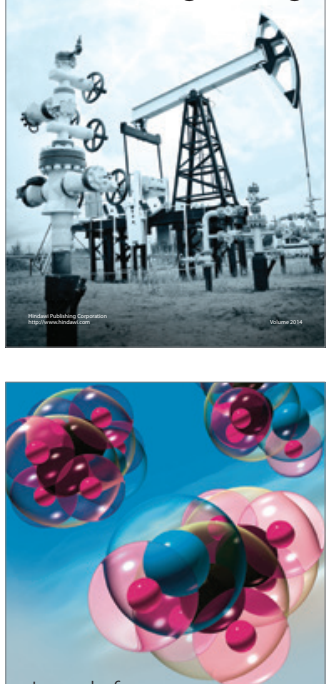

Fuels
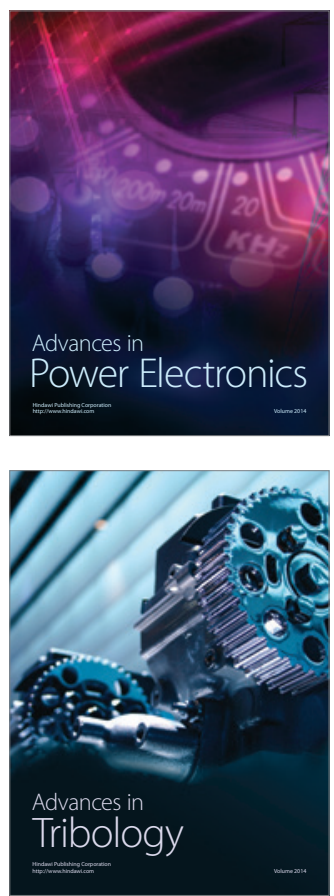

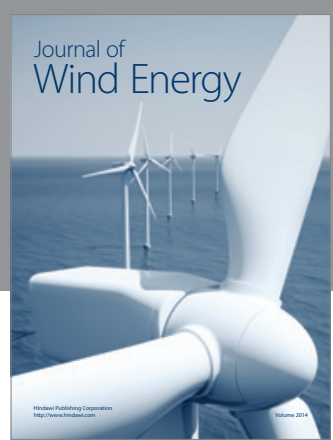

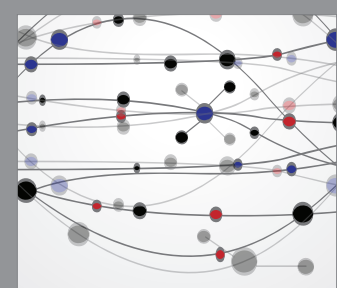

The Scientific World Journal

Submit your manuscripts at http://www.hindawi.com

Journal of

Structures
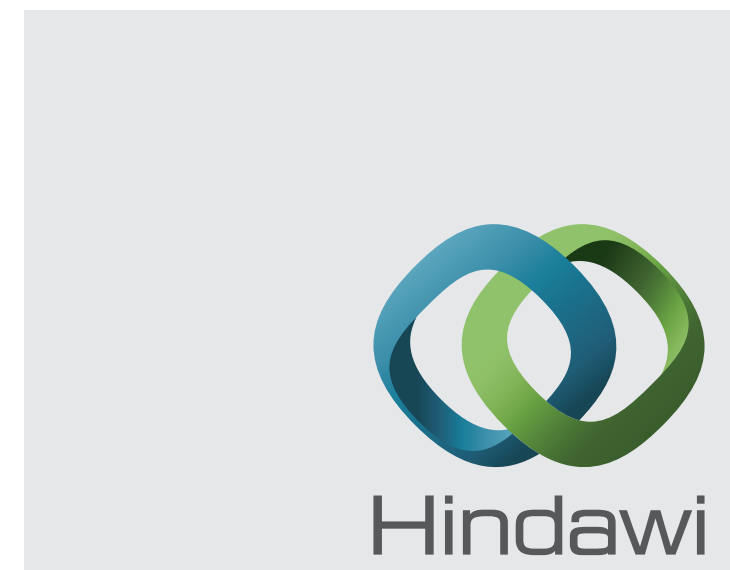

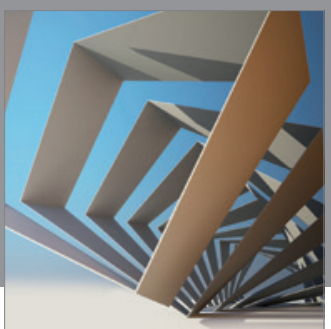

Rotating

Machinery
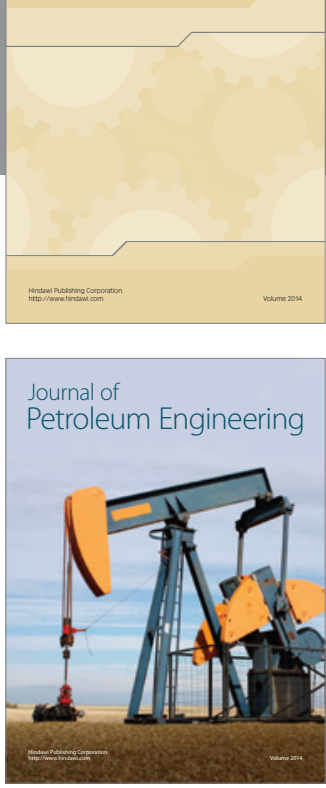

Journal of

Solar Energy
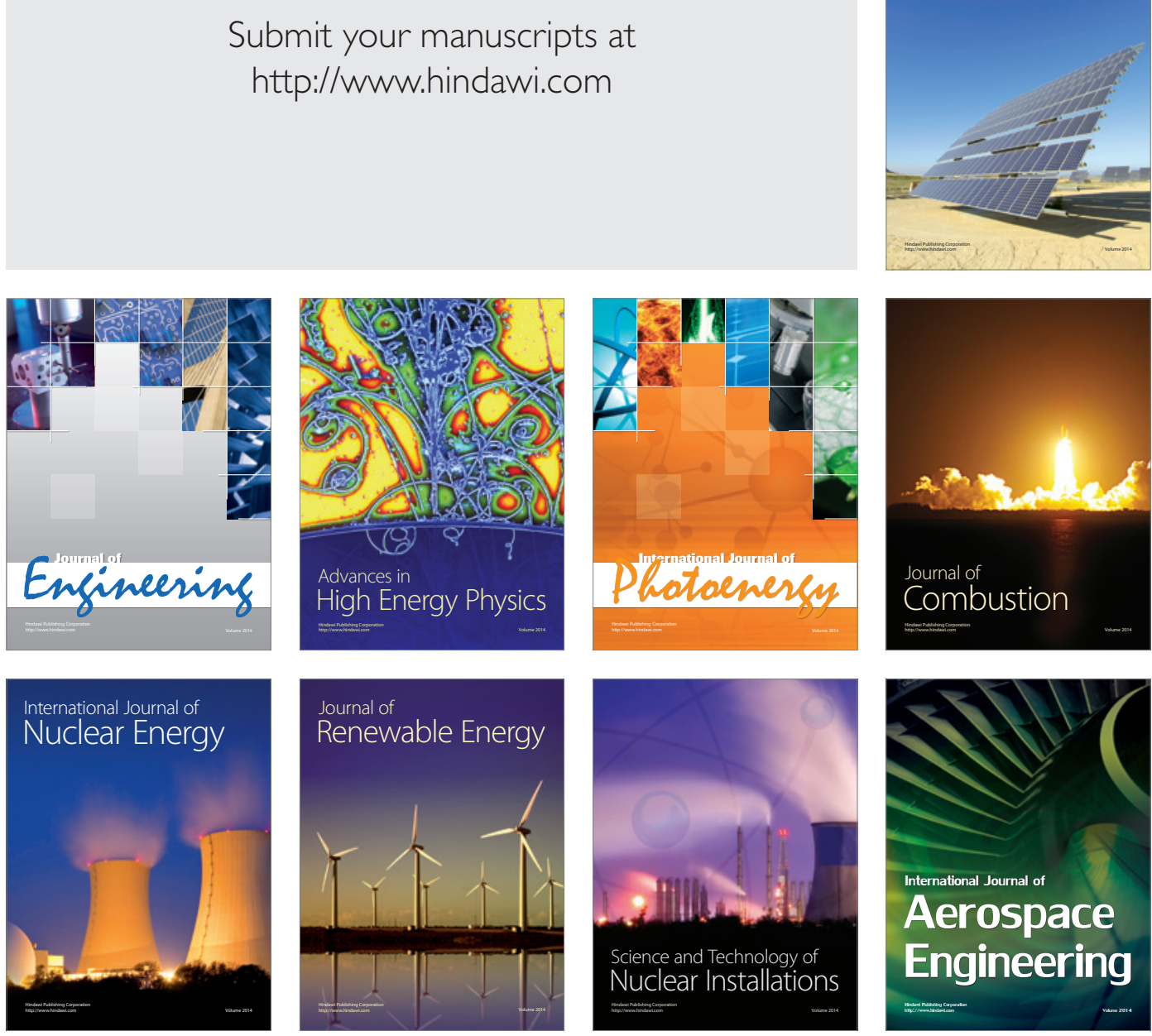